\title{
Synthesis and Computational Investigations of Ruthenium(II) Complexes Containing Hydrazine Schiff Base Ligands
}

\author{
S. Kamalesu ${ }^{1}$, K. Swarnalatha ${ }^{1^{*}}$ and R. Subramanian ${ }^{2}$ \\ ${ }^{1}$ Department of Chemistry, Manonmaniam Sundaranar University, Tirunelveli-12, Tamil Nadu, India \\ ${ }^{2}$ Centre for Scientific and Applied Research, School of Basic Engineering and Sciences, PSN College of \\ Engineering and Technology, Tirunelveli, Tamil Nadu 627152, India
}

\begin{abstract}
Three new heteroleptic ruthenium(II) complexes containing hydrazine schiff base as ligands were synthesized and characterized by using elemental analysis, FT-IR, ${ }^{1} \mathrm{H},{ }^{13} \mathrm{C} N \mathrm{NMR}$, and mass spectroscopic techniques. FT-IR study showed that the substituted phenylhydrazine ligands behave as a monoanionic bidentate $\mathrm{O}$ and $\mathrm{N}$ donors $(\mathrm{L})$ coordinate to ruthenium via the deprotonated phenolic oxygen and the azomethine nitrogen. They possess excellent thermal stabilities, evident from the thermal decomposition temperatures. Absorption, emission and electrochemical measurements were carried out and the structures of the synthesized complex were optimized using density functional theory (DFT). The molecular geometry, the highest occupied molecular orbital (HOMO), the lowest unoccupied molecular orbital (LUMO) energies, Mulliken atomic charges and molecular electrostatic potential (MEP) of the molecules are determined using B3LYP method and standard 6-311++G $(d, p)$ basis set.
\end{abstract}

Keywords: Ruthenium complex, hydrazine Schiff base ligands, DFT calculations, Energy gap, Electrostatic potential.

\section{INTRODUCTION}

The design and synthesis of organic-inorganic hybrid complexes based on strong coordinate bonds and multiple weak non-covalent forces has become a rapidly expanding field of research in coordination chemistry and crystal engineering. These complexes not only possess fascinating structural features but also show interesting properties as new functional materials, which can be used in the areas of luminescence, sensors, separation, adsorption, catalysis and biological chemistry [1, 2]. Polypyridyl ruthenium(II) complexes have been extensively studied attributable to their thermal stability, absorbing photochemical, photophysical and electrochemical properties, which can be adjusted by the insertion of various Lewis bases [3-6]. These features have driven the development of many applications of ruthenium(II) complexes catalysis [7-9] artificial photosynthetic system [10, 11], and sensors [12]. Among these applications, dye sensitized solar cells have got significant consideration as an alternative to conventional silicon photovoltaic devices $[5,13]$. Dye-sensitized solar cells (DSSCs) are an attractive solar energy conversion technology and their advantages include their low cost of manufacture, ease of fabrication and modifiable aesthetic features, such as colour and transparency [14]. A large number of molecular sensitizers, such as ruthenium-complex sensitizers and zinc porphyrin sensitizers, has been

${ }^{*}$ Correspondence Address to this author at the Department of Chemistry, Manonmaniam Sundaranar University, Tirunelveli-12, Tamil Nadu, India; Tel: 09994164804; Fax: 0462 2334363; E-mail: swarnalatha@msuniv.ac.in synthesized for the improvement of conversion efficiency of DSCs because the solar cell performances of the DSCs depend strongly on the photosensitizing ability of these sensitizers [15-17]. The electron transfer reactivity of the MLCT (metal to ligand charge transfer) excited states in polypyridyl-based complexes have long been used in many processes including electron transfer reagents and as dyes for solar photocells [18]. One of the most important requirements for the highly efficient sensitizers is a wide absorption, which covers whole visible and near-IR region as high as nearly $1000 \mathrm{~nm}$, with a large molar absorptivity. In addition, suitable energy levels of highest occupied molecular orbital (HOMO) and lowest unoccupied molecular orbitals (LUMO) are also important requirements for the highly efficient sensitizers because these enable effective electron-transfer reactions in the DSCs such as an electron injection from the photoexcited sensitizers into the conduction band of $\mathrm{TiO}_{2}$ and a regeneration of the resulting oxidized sensitizers by the redox mediator in the electrolyte solution [17]. And some of them have been characterized and tested in DSSCs. The $\mathrm{C}=\mathrm{N}$ unit is a polar double bond, which could not only increase the conjugation degree of the molecules but also effectively promote the transmission of the excited electron to prevent the electronic quenching and improve the photoelectric conversion efficiency. Azomethines are isoelectronic to their vinyl analogue and it has been demonstrated that azomethines possess similar optoelectronic properties. These materials have received very little attention as materials for organic electronics such as organic field 
effect transistors, electrochromic devices and organic photovoltaic devices. Monomer Schiff bases have been synthesized and regarded as dye sensitizers in solar cells, and showed a good performance [19-22]. Schiff base and their metal complexes that have optoelectric properties, high catalytic activity and could be used in photovoltaics with improvements have been listed. Schiff base compounds are very promising because of their biodegradability, non-toxicity, good electrical conductivity in conjugated compounds, and cheaper and easier production [23]. Copper and chrome are both vital and toxic for many biological systems. Thus, in the separation of $\mathrm{Cu}^{2+}$ and $\mathrm{Cr}^{3+}$ from aqueous solution using schiff base ligands. Hydrazines are also useful for the synthesis of metal complexes as they easily form stable complexes with most transition metal ions. Hydrazines and their metal complexes have gained a special attraction for widespread application in technology and analytical chemistry [24, 25]. Realizing the importance of the hydrazines and its derivatives as ligands, we have designed and proposed new ruthenium(II) complexes containing the hydrazine dervitative ligands. In the present paper, the selective synthesis and characterization of a three dinitro phenyl hydrazines containing ruthenium are reported, these synthesized compounds have theoretically investigated by using the more popular DFT methods, B3LYP, in 6$31++G(d, p)$ basis set. In order to make sense between the experimental and theoretical results, the electronic properties such as HOMO-LUMO energies, Mulliken atomic charges and molecular electrostatic potential (MEP) were calculated and the results were discussed. Moreover, the optical properties, thermal properties and electrochemical properties of metal complexes are also investigated in this paper.

\section{EXPERIMENTAL DETAILS}

\subsection{Materials and Instrumentation}

Commercially available $\mathrm{RuCl}_{3} \cdot 3 \mathrm{H}_{2} \mathrm{O}$ was used as supplied from Himedia Pvt. Ltd. 2,2'-bipyridine, 2,4dinitrophenylhydrazine, 2, 4-dihydroxybezaldehyde, 4(diethylamino)-2-hydroxybenzaldehyde, 2-hydroxy naphthaldehyde, lithium chloride were purchased from Sigma-Aldrich and were used as received. All other reagents used were chemically pure and analytical grade. Reagent grade organic solvents were purified and dried by recommended procedures [26] and degassed before use. Electrochemical measurements were carried out using $\mathrm{CHI600 \textrm {E }}$ Electrochemical Analyzer. A three-electrode assembly comprising glassy carbon as working electrode, Pt wire as counter electrode and $\mathrm{Ag} / \mathrm{AgCl}$ as reference electrode was used. The supporting electrolyte, tetrabutyl ammonium perchlorate (n-BuNClO), was dried in vacuum prior to use. cis- $\mathrm{Ru}(\mathrm{bpy})_{2} \mathrm{Cl}_{2} 2 \mathrm{H}_{2} \mathrm{O}$ was prepared following a published procedures [27]. Elemental analysis was done using a Perkin-Elmer elemental analyzer. A JASCO FT/IR-410 Spectrometer was used to record the IR spectra in the range of $4000-400 \mathrm{~cm}^{-1}$ using $\mathrm{KBr}$ pellets. The electronic spectra were recorded on a Perkin Elmer Lambda-25 UV-VIS spectrometer. ${ }^{1} \mathrm{H}$ NMR spectra was recorded on a Bruker AV III 400 $\mathrm{MHZ}$ instrument using TMS as an internal reference. Electron spray ionization mass spectra of the compound were recorded on a JEOL GCMATEII mass spectrometer using a positive mode in DMF solvent. The emission spectra were recorded by spectrofluorometer SL174 with Xenon lamp and the emission was fed into a monochromator where the emission intensity was recorded as a function of the wavelength. Thermal properties of the ruthenium complexes were studied by thermogravimetric analysis (TGA) which were carried out between $25^{\circ} \mathrm{C}$ and 900 ${ }^{\circ} \mathrm{C}$ in nitrogen atmosphere at a heating rate of $10{ }^{\circ} \mathrm{C}$ $\mathrm{min}^{-1}$ using NETZSCH STA 409 C/CD TGA instrument.

\subsection{Synthesis of Schiff Base Ligands}

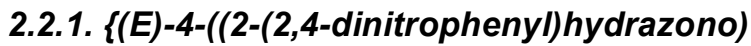 methyl)benzene-1,3-diol\} (2,4DNPH-2,4DHB) (L1)}

2, 4-dihydroxy bezaldehyde is condensed with 2,4dinitrophenyl hydrazine in 1:1 molar ratio in methanol solution $(10 \mathrm{ml})$. The reaction mixture was heated under reflux for $2 \mathrm{~h}$ and then concentrated to half of the initial volume. Red solid was formed on adding excess of anhydrous ether. The product was washed, dried and recrystallized from methanol. The purity of the schiff base ligand was checked by TLC. The yield of the isolated ligand was found to be $71 \%$. Anal.calcd. for $\mathrm{C}_{13} \mathrm{H}_{10} \mathrm{~N}_{4} \mathrm{O}_{6}(\%): \mathrm{C}, 49.06 ; \mathrm{H}, 3.17 ; \mathrm{N}, 17.61$. Found (\%): C, 49.10; H, 3.11; N, 17.56. IR $\left(\mathrm{KBr}, \mathrm{cm}^{-1}\right): 3436$ $\mathrm{v}_{\mathrm{OH}}, 1616 \mathrm{v}_{\mathrm{C}=\mathrm{N}}, 1258 \mathrm{v}_{\mathrm{C}-\mathrm{O}}$ (phenolic). ${ }^{1} \mathrm{H}$ NMR (DMSO-d $\left.\mathrm{d}_{6}\right): \delta$ (ppm): $11.60(\mathrm{~s} 1 \mathrm{H}, \mathrm{OH}) 9.97(\mathrm{~s}, 1 \mathrm{H}, \mathrm{NH}), 8.85(\mathrm{~s}, 1 \mathrm{H}$ $\mathrm{HC}=\mathrm{N}$ ), 6.34-8.86 (m, $6 \mathrm{H}$ aromatic), ${ }^{13} \mathrm{C}$ NMR (DMSO$\left.\mathrm{d}_{6}\right): \delta(\mathrm{ppm}): 144.76(\mathrm{CH}=\mathrm{N}), 104.02-158.16$ (aromatic carbon).

\subsection{2. $\{(E)-5-($ diethylamino)-2-((2-(2,4-dinitrophenyl) hydrazono)methyl)phenol\} (2,4DNPH-DEAS) (L2)}

It was prepared by using the same procedure as described for L1 with 4-(diethylamino)-2hydroxybenzaldehyde $(1 \mathrm{mmol})$, and 2,4-dinitrophenyl hydrazine $(1 \mathrm{mmol})$. A red product was formed. The 
solid compound was filtered, washed and recrystallized from methanol. Yield: $75 \%$ Anal.calcd for $\mathrm{C}_{17} \mathrm{H}_{19} \mathrm{~N}_{5} \mathrm{O}_{5}$ (\%): C, 54.69; H, 5.13; N, 18.76. Found (\%): C, 54.62; $\mathrm{H}, 5.16 ; \mathrm{N}, 18.70$. IR $\left(\mathrm{KBr}, \mathrm{cm}^{-1}\right): 3427 \mathrm{~V}_{\mathrm{OH}}, 1618 \mathrm{~V}_{\mathrm{C}=\mathrm{N}}$, $1243 \mathrm{v}_{\mathrm{C}-\mathrm{O} \text { (phenolic). }}{ }^{1} \mathrm{H}$ NMR (DMSO-d $\left.\mathrm{d}_{6}\right): \delta$ (ppm): 11.56 (s $1 \mathrm{H}, \mathrm{OH}) 9.97(\mathrm{~s}, 1 \mathrm{H}, \mathrm{NH}), 8.73(\mathrm{~s}, 1 \mathrm{H} \mathrm{HC}=\mathrm{N}), 6.13-8.85$ (m, $6 \mathrm{H}$ aromatic), ${ }^{13} \mathrm{C}$ NMR (DMSO-d $)$ : $\delta$ (ppm): $144.45(\mathrm{CH}=\mathrm{N}), 103.25-161.05$ (aromatic carbon).

\subsection{3. $\{(E)-1-((2-(2,4-d i n i t r o p h e n y l) h y d r a z o n o)$ methyl)naphthalen-2-ol \} (2,4DNPH-2NA) (L3)}

It was prepared by using the same procedure as described for L1 with 2-hydroxy naphthaldehyde (1 $\mathrm{mmol})$, and 2,4-dinitro phenyl hydrazine $(1 \mathrm{mmol})$. A red product was formed. The solid compound was filtered, washed and recrystallized from methanol. Yield: $85 \%$ Anal.calcd. for $\mathrm{C}_{17} \mathrm{H}_{12} \mathrm{~N}_{4} \mathrm{O}_{5}$ (\%): C, 57.96; $\mathrm{H}$, 3.43; N, 15.90. Found (\%): C, 57.91; H, 3.41; N, 15.86 . $\mathrm{IR}\left(\mathrm{KBr}, \mathrm{cm}^{-1}\right): 3445 \mathrm{v}_{\mathrm{OH}}, 1612 \mathrm{v}_{\mathrm{C}=\mathrm{N}}, 1254 \mathrm{v}_{\mathrm{C}-\mathrm{O} \text { (phenolic). }}{ }^{1} \mathrm{H}$ NMR (DMSO-d $\left.\mathrm{d}_{6}\right): \delta$ (ppm): $11.79(\mathrm{~s} 1 \mathrm{H}, \mathrm{OH}) 11.10$ (s, $1 \mathrm{H}, \mathrm{NH}), 9.15(\mathrm{~s}, 1 \mathrm{H} \mathrm{HC}=\mathrm{N}), \quad 7.25-8.86(\mathrm{~m}, 9 \mathrm{H}$ aromatic), ${ }^{13} \mathrm{C}$ NMR (DMSO-d $\left.\mathrm{d}_{6}\right): \delta$ (ppm): 144.50 $(\mathrm{CH}=\mathrm{N}), 109.05-171.20$ (aromatic).

\subsection{Preparation of Ruthenium(II) Complexes}

\subsubsection{Synthesis of $\left[R u(b p y)_{2} L 1\right]$ (ML1)}

Schiff base ligand L1 $(0.0657 \mathrm{~g}, 1 \mathrm{mmol})$ was added to solution of $\mathrm{Ru}(\mathrm{bpy})_{2} \mathrm{Cl}_{2}(0.100 \mathrm{~g}, 1 \mathrm{mmol})$, in $50 \mathrm{~mL}$ of DMF. The resulting mixture was refluxed under a nitrogen atmosphere for 7 hours. After refluxing, $50 \mathrm{~mL}$ of acetone was added to the refluxing mixture. The purple solution turned reddish brown and was kept in the refrigerator for overnight. The brown precipitate formed was filtered and washed thoroughly with diethyl ether. This solid was crystallized from DMF/hexane mixture. (Yield 65\%). Anal.calcd. for $\mathrm{C}_{33} \mathrm{H}_{25} \mathrm{~N}_{8} \mathrm{O}_{6} \mathrm{Ru}$ (\%): C, 54.25; $\mathrm{H}, 3.45 ; \mathrm{N}, 15.34$. Found (\%): C, 54.19; $\mathrm{H}, 3.48 ; \mathrm{N}, 15.31$. IR $\left(\mathrm{KBr}, \mathrm{cm}^{-1}\right): 1595 \mathrm{v}_{\mathrm{C}=\mathrm{N}}, 1272 \mathrm{v}_{\mathrm{C}-\mathrm{O}}$, $508 \mathrm{v}_{\mathrm{M}-\mathrm{O}}, 466 \mathrm{v}_{\mathrm{M}-\mathrm{N} .}{ }^{1} \mathrm{H}$ NMR (DMSO-d 6 ): $\delta$ (ppm): 9.83 (s, $1 \mathrm{H}, \mathrm{NH}), 9.25$ (s, $1 \mathrm{H} \mathrm{HC}=\mathrm{N}), 6.13-8.87(\mathrm{~m}, 22 \mathrm{H}$ aromatic), ${ }^{13} \mathrm{C}$ NMR (DMSO- $\left.\mathrm{d}_{6}\right): \quad \delta \quad(\mathrm{ppm})$ : 156.78 $(\mathrm{CH}=\mathrm{N}), 103.42-159.94$ (aromatic carbon).

\subsubsection{Synthesis of $\left[R u(b p y)_{2} L 2\right](M L 2)$}

Same procedure was adopted to obtain ML2 using L2 $(0.077 \mathrm{~g}, 1 \mathrm{mmol})$ and $\mathrm{Ru}(\mathrm{bpy})_{2} \mathrm{Cl}_{2}(0.100 \mathrm{~g}, 1$ $\mathrm{mmol})$. Reddish brown colored crystalline powder was obtained. Yield: $67 \%$. Anal.calcd. for $\mathrm{C}_{37} \mathrm{H}_{34} \mathrm{~N}_{9} \mathrm{O}_{5} \mathrm{Ru}$ (\%): $\mathrm{C}, 56.55 ; \mathrm{H}, 4.36 ; \mathrm{N}, 16.04$. Found (\%): C, 56.51; $\mathrm{H}, 4.32 ; \mathrm{N}, 16.10 . \mathrm{IR}\left(\mathrm{KBr}, \mathrm{cm}^{-1}\right): 1600 \mathrm{v}_{\mathrm{C}=\mathrm{N}}, 1266 \mathrm{v}_{\mathrm{C}-\mathrm{O}}$, $505 \mathrm{v}_{\mathrm{M}-\mathrm{O}}, 456 \mathrm{v}_{\mathrm{M}-\mathrm{N} .}{ }^{1} \mathrm{H}$ NMR (DMSO-d 6 ): $\delta(\mathrm{ppm}): 9.85$ (s, 1H, NH), $9.14(\mathrm{~s}, 1 \mathrm{H} \mathrm{HC}=\mathrm{N}), 6.23-8.80(\mathrm{~m}, 22 \mathrm{H}$ aromatic) ${ }^{13} \mathrm{C}$ NMR (DMSO-d $\mathrm{d}_{6}$ ): $\delta$ (ppm): 156.28 $(\mathrm{CH}=\mathrm{N}), 101.20-159.32$ (aromatic carbon), 47.84 ($\mathrm{CH} 3), 13.46(-\mathrm{CH} 2)$.

\subsubsection{Synthesis of $\left[R u(b p y)_{2} L 3\right](M L 3)$}

It was prepared using the same procedure as described for ML1 using L3 (0.072 g, $1 \mathrm{mmol})$ and $\mathrm{Ru}(\mathrm{bpy})_{2} \mathrm{Cl}_{2}(0.100 \mathrm{~g}, 1 \mathrm{mmol})$. Reddish brown colored crystalline powder was obtained. Yield: $68 \%$. Anal.calcd. for $\mathrm{C}_{37} \mathrm{H}_{27} \mathrm{~N}_{8} \mathrm{O}_{5} \mathrm{Ru}(\%)$ : C, 58.11; H, 3.56; N, 14.65. Found (\%): C, 58.15; $\mathrm{H}, 3.51 ; \mathrm{N}, 14.61$. IR ( $\mathrm{KBr}$, $\left.\mathrm{cm}^{-1}\right): 1599 \mathrm{v}_{\mathrm{C}=\mathrm{N}}, 1262 \mathrm{v}_{\mathrm{C}-\mathrm{O},}, 490 \mathrm{v}_{\mathrm{M}-\mathrm{O}}, 461 \mathrm{v}_{\mathrm{M}-\mathrm{N} .}{ }^{1} \mathrm{H}$ NMR (DMSO-d 6 ): $\delta(\mathrm{ppm}): 11.16(\mathrm{~s}, 1 \mathrm{H}, \mathrm{NH}), 9.76(\mathrm{~s}, 1 \mathrm{H}$ $\mathrm{HC}=\mathrm{N}), \quad 8.96-6.92(\mathrm{~m}, \quad 25 \mathrm{H}$ aromatic $),{ }^{13} \mathrm{C}$ NMR $\left(\right.$ DMSO- $\left._{6}\right): \delta(\mathrm{ppm}): 156.88(\mathrm{CH}=\mathrm{N}), 108.93-154.32$ (aromatic).

\subsection{Computational Methods}

All calculations were performed using Gaussian 09 software package [28], at the B3LYP/6-311++G(d,p) level of theory. The DFT methods are low computational cost and more advantageous owing to their accuracy. These properties make DFT more sensible and realistic for the computations of different molecules. Transitions to the lowest excited singlet electronic states of ruthenium complexes were computed by using the gradient corrected DFT with the three-parameter hybrid functional Becke3 (B3) for the exchange part and the Lee-Yang-Parr (LYP) correlation function, HOMO-LUMO energy level calculations and Geometry optimization have been carried out in the present investigation, using $6-311++G(d, p)$ Basis set with Gaussian 09W program package [29]. The chemical reactivity descriptors were calculated using DFT. These are very important physical parameters to understand the chemical and physical activities of the ruthenium complexes. The calculated HOMO-LUMO orbital energies can be used to estimate the ionization energy (IE) $=-\varepsilon_{\text {HOMO }}$, electron affinity $(\mathrm{EA})=-\varepsilon_{\text {LUMO }}$, electronegativity $(\chi)=(\mathrm{IE}+\mathrm{EA}) / 2$, LUMO electronic chemical potential $(\mu)=-\chi$, chemical hardness $(\eta)=(\mathrm{IE}-$ $\mathrm{EA}) / 2$, chemical softness $(\sigma)=1 / \eta$, electrophilicity index $(\omega)=\mu 2 / 2 \eta[29,30]$.

\section{RESULTS AND DISCUSSION}

Analytical and spectroscopic data for the ligands and its complexes indicate a 1:1 metal-ligand stoichiometry for all the complexes. The synthetic route of the complexes and the proposed structure of the complexes are shown in Scheme 1. The complexes are 


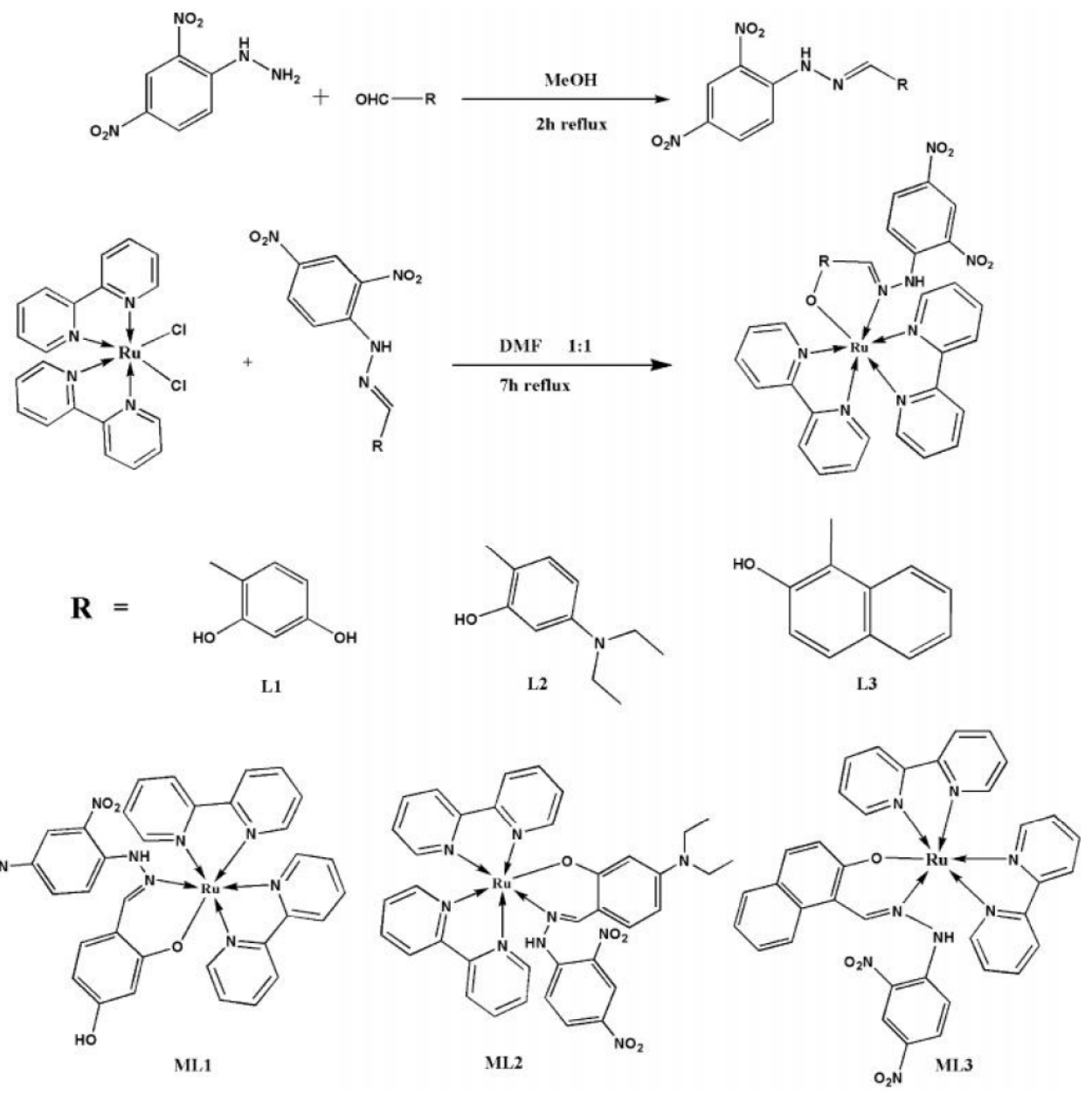

Scheme 1: Synthetic route of ligands and complexes ML1, ML2 and ML3.

soluble in most common organic solvents like DMF and DMSO.

\subsection{FT-IR Spectral Features}

The IR spectra of free Schiff bases were compared with those of the ruthenium complexes in order to ascertain the binding mode of the Schiff base ligands to the ruthenium metal ion in the complexes (Table S1, Figure 1). A strong band at $1243-1261 \mathrm{~cm}^{-1}$ in the free ligands can be assigned to phenolic $\mathrm{C}-\mathrm{O}$ stretching. This band shifted to $1262-1360 \mathrm{~cm}^{-1}$ in complexes, showing that the coordination through the phenolic oxygen via deprotonation [31]. This is supported by the disappearance of the $v_{\mathrm{O}-\mathrm{H}}$ band in all the complexes which observed in free ligands around $3415-3439 \mathrm{~cm}^{-1}$ , whereas in ML1 a broad peak appeared in the same region due to the presence of $p$-hydroxy group in the ligand. The band around 1611-1638 $\mathrm{cm}^{-1}$ in the spectra of ligands can be attributed to $v_{\mathrm{C}=\mathrm{N}}$ which is shifted to $1595-1629 \mathrm{~cm}^{-1}$ in complexes indicating the coordination of azomethine nitrogen with central metal ion $\left[32,33\right.$. The spectral range $\sim 1600-1400 \mathrm{~cm}^{-1}$ associated with stretching vibrations of pyridyl rings. The formation of the $\mathrm{M}-\mathrm{O}$ and $\mathrm{M}-\mathrm{N}$ bonds was further supported by the appearance of the $\mathrm{v}_{(\mathrm{M}-\mathrm{O})}$ and $\mathrm{v}_{(\mathrm{M}-\mathrm{N})}$ bands in the regions $455-475$ and $541-480 \mathrm{~cm}^{-1}$ respectively [34-36]. The IR spectra of all the complexes therefore confirms the coordination mode of the phenyl hydrazine schiff base ligand to ruthenium(II) ion via the azomethine nitrogen and the phenolic oxygen. The most important conclusion drawn from the infrared spectral evidence is that the Schiff base ligand acts as a bidentate ligand towards the central ruthenium ions via one azomethine nitrogen atoms and one negatively charged oxygen atoms.

\section{2. ${ }^{1} \mathrm{H}$ and ${ }^{13} \mathrm{C}$ NMR Spectra Analysis}

Coordination of the ligands with the metal atom was further confirmed by using ${ }^{1} \mathrm{H}$ NMR spectral analyses (Table S2, S3. Figures a1-a12, Supporting material). The spectra of the free ligands have showed a signal at 11.6-11.8 ppm characteristics of phenolic $-\mathrm{OH}$ proton which have disappeared in their complexes, suggesting the coordination of deprotonated phenolic oxygen [37]. 


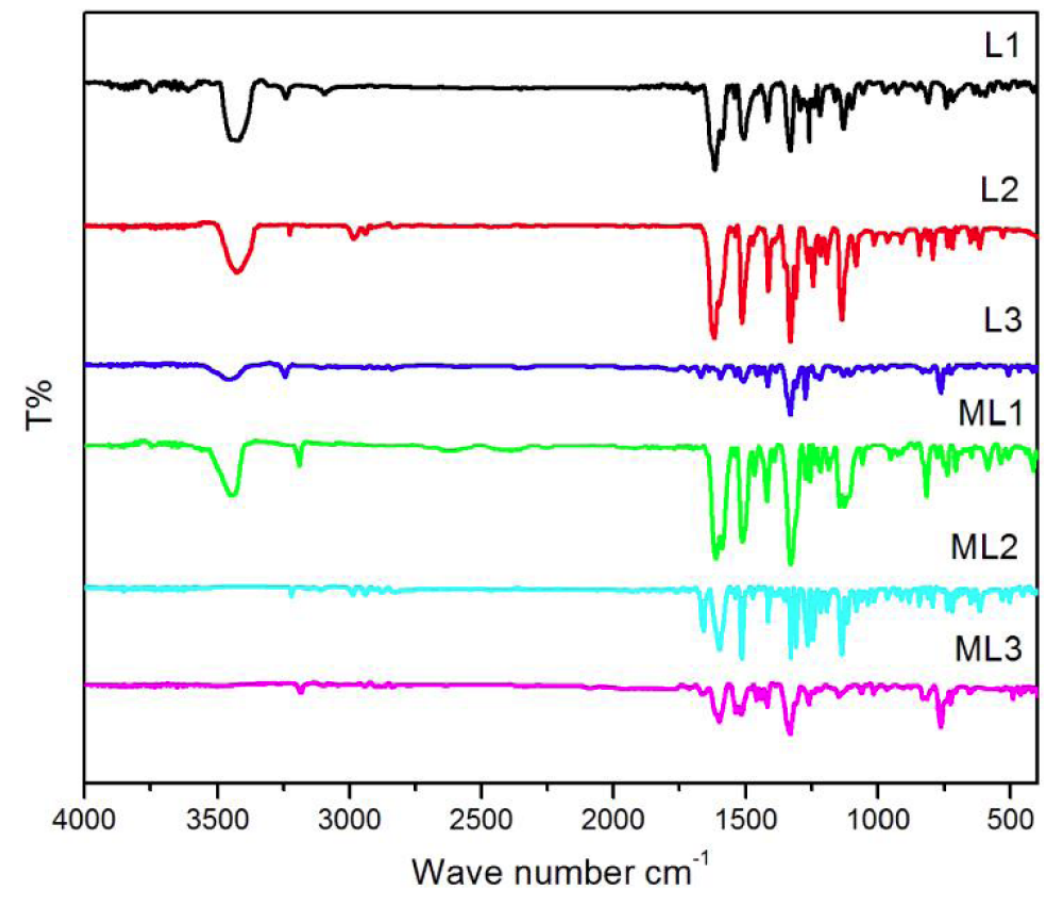

Figure 1: FT-IR Spectra of Schiff base ligands and complexes.

A singlet observed at 8.7-9.2 ppm in the spectra of the free ligands has been assigned to azomethine proton which has undergone a downfield shift around 9.8-9.1 $\mathrm{ppm}$ in the complexes indicating the coordination of azomethine nitrogen to ruthenium metal [37-40]. The complexes have shown their aromatic protons of the phenolic group and bipyridine ligands have exhibited their signal in the region 6.1-8.9 ppm The above observations made it clear that the ligands have coordinated to the ruthenium(II) ion.

The ${ }^{13} \mathrm{C}$ NMR of all the $\mathrm{Ru}(\mathrm{II})$ complexes showed in the expected regions. The complexes ( $\delta 157-155 \mathrm{ppm})$ revealed a downfield shift of the azomethine carbon $(-\mathrm{C}=\mathrm{N}-)$ relative to the free ligands $(\delta 146-144 \mathrm{ppm})$ indicating coordination of the azomethine nitrogen to the metal centre. A sharp singlet at $\delta 47.84$ and 13.46 ppm are assigned to ethyl carbon. This confirms the formation of new ruthenium(II) hydrazone Schiff base complexes $[39,40]$.

\subsection{Mass Spectra Analysis}

The mass spectra of the ruthenium(II) complexes is in good agreement with the proposed molecular structure and the mass spectra of the complex is shown in Figures a13-a15, the peak shows the $\mathrm{M}+\mathrm{Cl}$ appears at $\mathrm{m} / \mathrm{z}=766.31,821.19$ and 799.42. The molecular ion peak, $[\mathrm{M}+\mathrm{H}]$ appears at $\mathrm{m} / \mathrm{z}=731.56$, 786.69 and 765.68 confirms the stoichiometry of the complexes ML1, ML2, and ML3 respectively.

\subsection{Electronic Spectra}

Electronic spectra of all the nuclear $\mathrm{Ru}(\mathrm{II})$ complexes showed intense absorptions in the ultraviolet and visible region. The electronic spectra of all the complexes have been recorded in DMF and displayed four intense absorptions in the region 800$200 \mathrm{~nm}$. The electronic spectral data of complexes 1-3 are listed in (Table 1) and selected spectra is shown in Figure 2. The absorption in the visible region at 530$546 \mathrm{~nm}$ is due to $d-d$ transition and the bands observed in the region $302-378 \mathrm{~nm}$ are due to $n-\pi^{*}$ transition of non-bonding electrons present on the nitrogen of the azomethine group in the ruthenium(II) complexes. The band observed around $254-260 \mathrm{~nm}$ is assigned to $\pi-$ $\pi^{*}$ transitions of the ligand. The pattern of the electronic spectra of all the complexes indicate the presence of an octahedral environment around ruthenium(III) similar to that of other ruthenium(II) octahedral complexes [41-43].

\subsection{Emission Spectra}

Photoluminescent spectra of the three ruthenium complexes in DMF solution in room temperature is shown in Figure 3. The excitation wavelengths were set to the absorption maxima from the UV-vis absorption spectra, as $525 \mathrm{~nm}$. It can be seen that the broad emission band of complexes ML1, ML2 and ML3 is $604,609,613 \mathrm{~nm}$ respectively. 
Table 1: The Absorption and Emission Spectral Data of the Complexs ML1, ML2, and ML3

\begin{tabular}{|c|c|c|}
\hline Compounds & UV spectral data $\left(\varepsilon_{\max }, \mathbf{M}^{-1} \mathbf{c m}^{-1}\right)^{*}$ & $\begin{array}{c}\text { Emission } \\
\lambda(\mathbf{n m})\end{array}$ \\
\hline \hline ML1 & $255,289,341,541(12,220)$ & 604 \\
\hline ML2 & $259,302,547(12,390)$ & 610 \\
\hline ML3 & $256,303,360,528(18,020)$ & 614 \\
\hline
\end{tabular}

*(The values in the parenthesis are molar absorption coefficients).

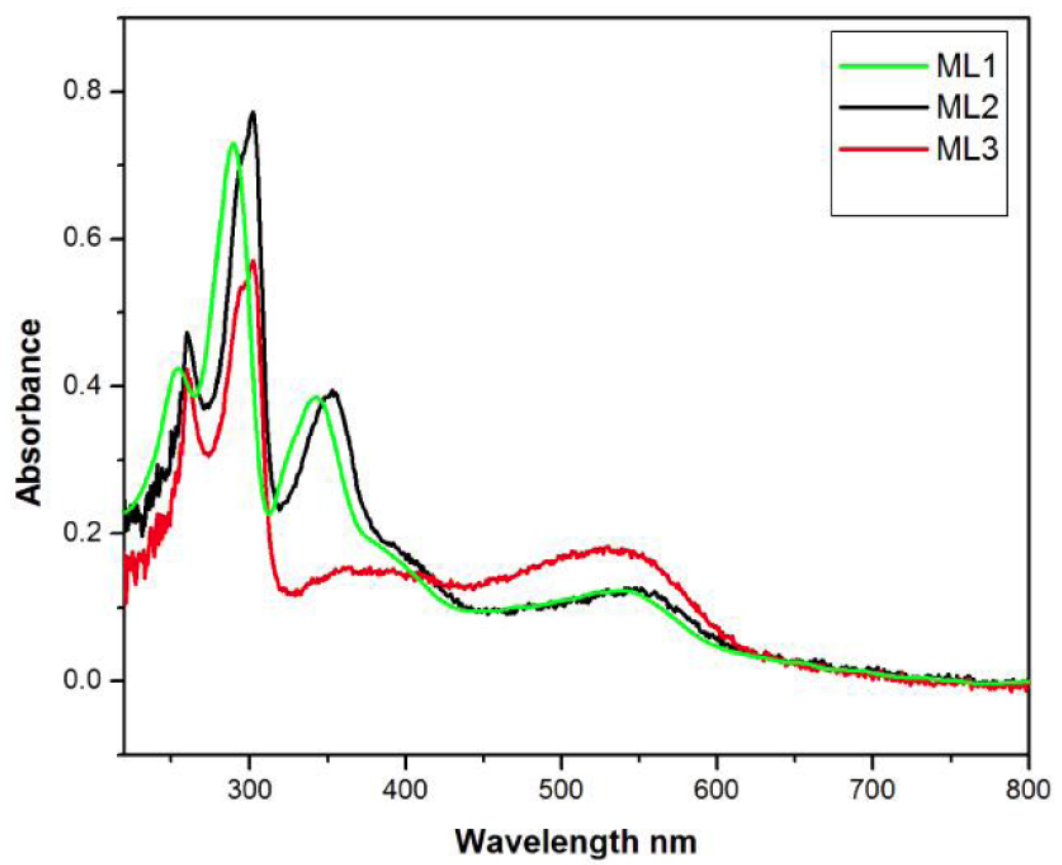

Figure 2: Absorption spectra of the ruthenium(II) complexes in DMF.

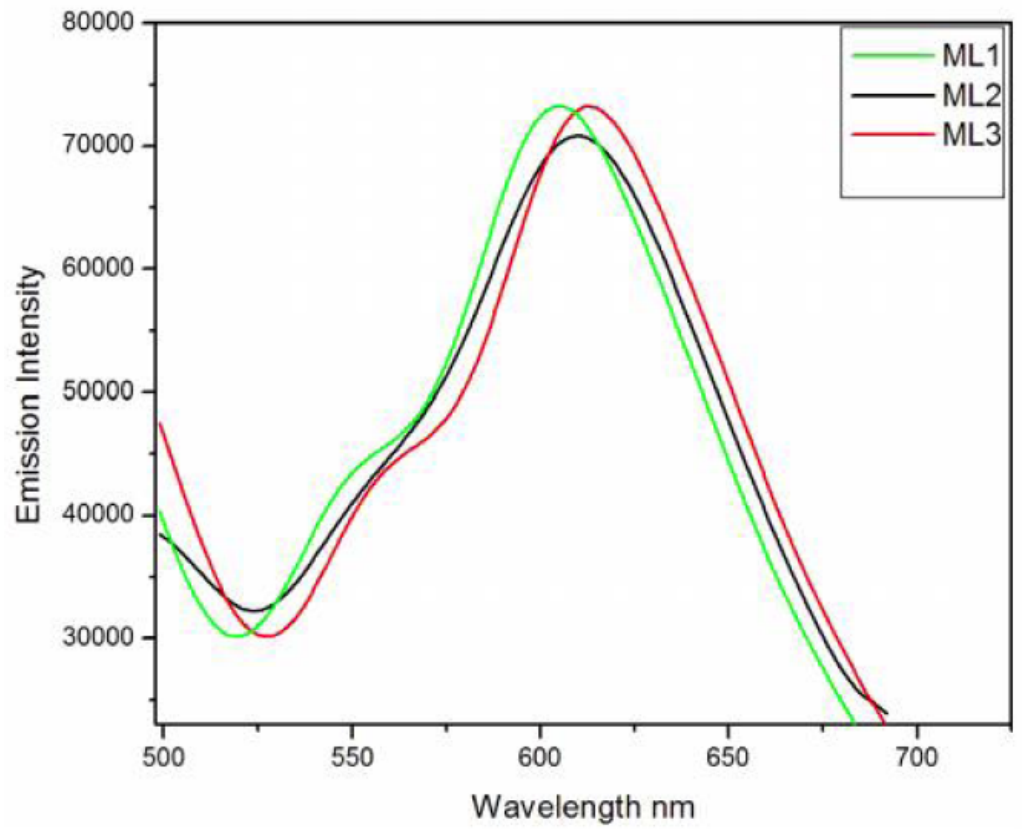

Figure 3: Emission spectra of the complexes ML1, ML2 and ML3 in DMF (ex at $525 \mathrm{~nm}$ ). 
Table 2: Thermogravimetric Data of Ruthenium Complexes

\begin{tabular}{|c|c|c|c|}
\hline Complex & Temperature Range $\mathbf{T}\left({ }^{\circ} \mathrm{C}\right)$ & \% weight loss Obs. (calcd.) & Process \\
\hline \hline $\mathrm{ML} 1$ & $196-565,>565$ & $86.38(86.16) 13.62(13.84)$ & loss of organic moiety, $\mathrm{Ru}_{2} \mathrm{O}_{3}$ \\
\hline $\mathrm{ML} 2$ & $192-560,>560$ & $87.43(87.14) 12.57(12.86)$ & loss of organic moiety, $\mathrm{Ru}_{2} \mathrm{O}_{3}$ \\
\hline $\mathrm{ML} 3$ & $198-560,>560$ & $86.62(86.78) 13.38(13.22)$ & loss of organic moiety, $\mathrm{Ru}_{2} \mathrm{O}_{3}$ \\
\hline
\end{tabular}

\subsection{Thermal Analysis}

The thermal stability data of the complexes are listed in Table 2. The ML1, ML2 and ML3 complexes undergo the similar type of decompositions (Figures a16-a18). The complexes $\left[R u(b p y){ }_{2} L\right]$ decomposition in single stage. The decomposition step is represented by the complete removal of the organic ligand moiety in the $192-565{ }^{\circ} \mathrm{C}$ range with the formation of matal oxide as the final product. The TG curves of the complex [Ru (bpy) $)_{2}$ L1] showing a weight loss of $86.38 \%$ (calculated - $86.16 \%$ ) in the temperature range $196-565^{\circ} \mathrm{C}$ is due to the decomposition of coordinated organic ligand. Above this temperature, horizontal thermal curve has been observed due to the formation of the metal oxide. The TG curves of the complex [Ru (bpy) $)_{2}$ L2] showing a weight loss $87.43 \%$ (calculated - $87.14 \%$ ) the temperature range $192-560{ }^{\circ} \mathrm{C}$ showing the elimination of the coordinated organic ligand. The complex $\left[\mathrm{Ru}(\mathrm{bpy})_{2} \mathrm{~L} 3\right]$ shows a similar trend of decomposition process. The first stage taking place in the $198-560{ }^{\circ} \mathrm{C}$ range is attributed to the expulsion of the organic ligand molecule and it is in agreement with the calculated mass loss [44].

\subsection{Electrochemical Properties}

The electrochemical properties of the ruthenium complexes were studied in DMSO solution by cyclic voltammetry using a glassy carbon electrode, tetrabutylammonium perchlorate as supporting electrolyte and the potentials are expressed with reference to $\mathrm{Ag} / \mathrm{AgCl}$. And the cyclic voltammograms are given in Figure 4. From the onset oxidation potentials $\left(E_{o x}\right)$ and the onset reduction potentials $\left(E_{\text {red }}\right)$ of the complexes, HOMO, and LUMO energy levels as well as the energy gap of the complexes were calculated according to the equations,

$$
\begin{aligned}
& \text { HOMO }=-\left(E_{\text {ox }}+4.40\right)(\mathrm{eV}) \\
& \text { LUMO }=-\left(E_{\text {red }}+4.40\right)(\mathrm{eV})
\end{aligned}
$$

The reduction and oxidation potentials of ruthenium complex (ML1) were measured to be $E_{\text {red }}=-0.8645 \mathrm{~V}$ and $E_{o x}=0.9695 \mathrm{~V}$, respectively, and the energy bandgap was $1.834 \mathrm{eV}$, the energy value of the HOMO was calculated to be $-5.3695 \mathrm{eV}$ and for LUMO was $3.5355 \mathrm{eV}$. The oxidation and reduction potentials revealed in cyclic voltammograms showed the highest occupied molecular orbital (HOMO) and lowest unoccupied molecular orbital (LUMO) levels, which correspond to ionization potentials and electron affinities, respectively. Similarly the redox potential values for ML2 and ML3 are determined and tabulated in Table 3 [45].

\section{COMPUTATIONAL RESULTS}

As mentioned earlier, all the calculations were applied in B3LYP method in $6-311++G(d, p)$ basis set. The optimized structure of ruthenium complexes along with labeling of atoms is shown in Figure $\mathbf{5}$ as ball and stick model. The geometry optimization yields a non planar structure. Also, the most optimized structural parameters of complexes ML1, ML2 and ML3 calculated by B3LYP/6- $311++G(d, p)$ are presented in Table S4.

\subsection{Electronic Properties}

The electronic absorption corresponds to the transition from the ground to the first excited state and is mainly described by one electron excitation from the highest occupied molecular orbital (HOMO) to the lowest unoccupied molecular orbital (LUMO). The HOMO represents the ability to donate an electron, LUMO as an electron acceptor represents the ability to obtain an electron. Both HOMO and LUMO are the main orbitals that take part in chemical stability. The HOMO-LUMO energies are computed at B3LYP/6$311 G(d)$ level of theory [46]. These orbitals play an important role in the electric properties and determine the way the molecule interacts with other species. Both the HOMO and the LUMO are the main orbital taking part in chemical reaction. While the energy of the HOMO is directly related to the ionization potential, LUMO energy is directly related to the electron affinity. Also, the frontier orbital gap, the energy gap between 


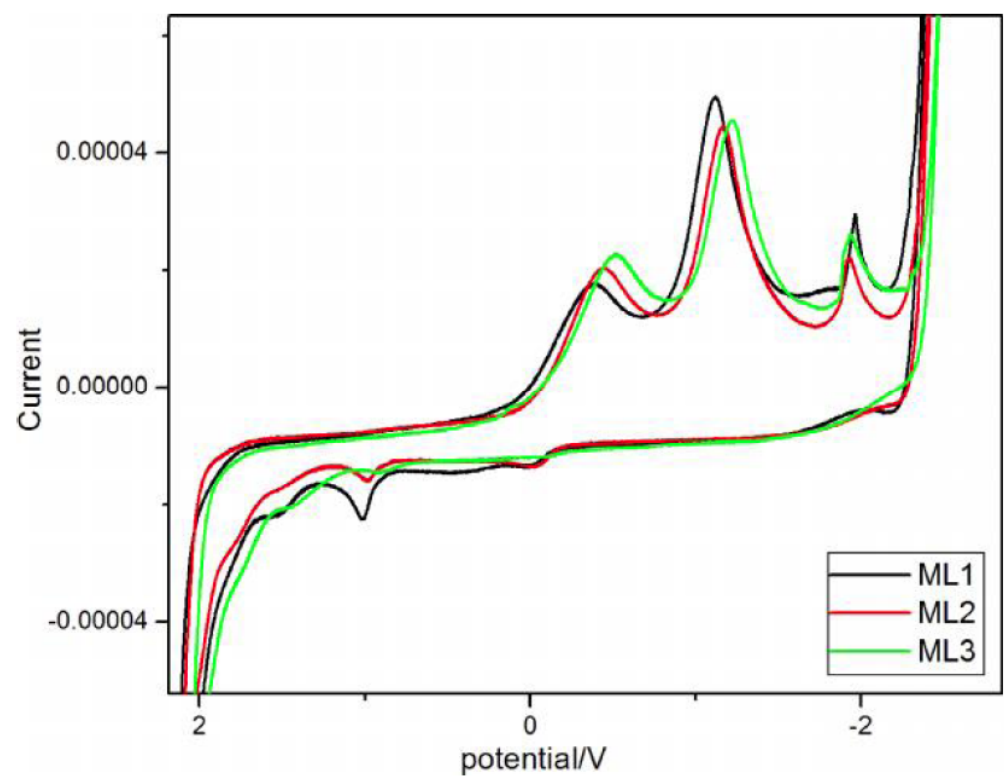

Figure 4: Cyclic voltammograms of complex ML1, ML2, and ML3 measured in DMSO solution. [tetra butyl ammonium perchlorate as supporting electrolyte, Scan rate $=0.1 \mathrm{~V} / \mathrm{s}$ ].

Table 3: Cyclic Voltammetric Results of Complexes ML1, ML2 and ML3

\begin{tabular}{|c|c|c|c|c|}
\hline Complexes & $\mathbf{E}^{\text {ox }}{ }_{\text {onset }}(\mathrm{V})$ & $\mathbf{E}_{\text {onset }}^{\text {red }}(\mathrm{V})$ & HOMO (eV) & LUMO (eV) \\
\hline \hline ML1 & 0.9695 & -0.8645 & -5.3695 & -3.5355 \\
\hline ML2 & 0.9462 & -0.9896 & -5.3896 & -3.4538 \\
\hline ML3 & 0.7829 & -0.9725 & -5.6707 & -3.4257 \\
\hline
\end{tabular}

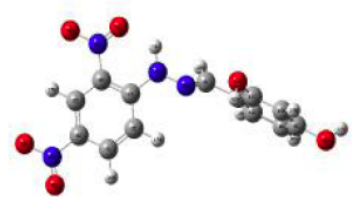

HL1

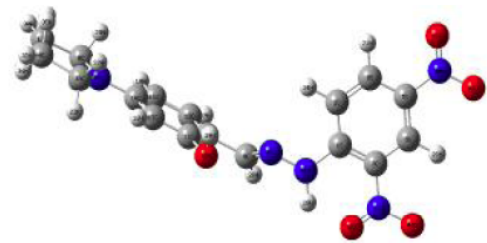

HL2

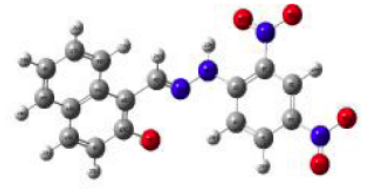

HL3

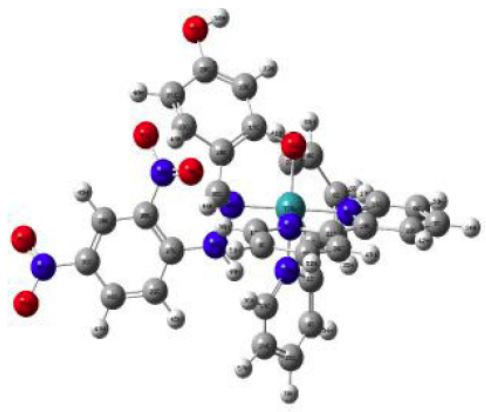

ML1

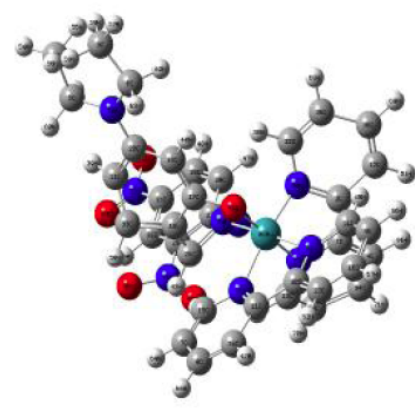

ML2

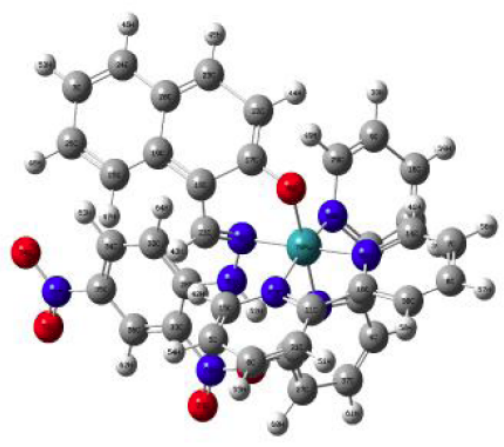

ML3

Figure 5: Optimized structure of Ligands L1, L2, L3 and complex ML1, ML2, ML3 within numbering of atoms obtained at $B 3 L Y P / 6-311++G(d, p)$ level of theory. 
Table 4: Energetic Properties, Dipole Moments, Energies of HOMO, LUMO Orbitals and Energy Gap

\begin{tabular}{|c|c|c|c|c|c|c|c|c|c|c|c|c|}
\hline Compound & $\begin{array}{c}\text { HOMO } \\
(\mathrm{eV})\end{array}$ & $\begin{array}{l}\text { LUMO } \\
\text { (eV) }\end{array}$ & $\begin{array}{c}\text { Energy } \\
\text { gap (eV) }\end{array}$ & IP (eV) & $\mathrm{EA}(\mathrm{eV})$ & $x(e V)$ & $\mu(\mathrm{eV})$ & $\eta(\mathrm{eV})$ & $\sigma(\mathrm{eV})$ & $\omega(e V)$ & $\begin{array}{l}\text { Etotal } \\
\text { (a. u) }\end{array}$ & $\underset{\text { (Debye) }}{\mu}$ \\
\hline L1 & -5.6761 & -2.4467 & 3.2293 & 5.6761 & 2.4467 & 4.0614 & -4.0614 & 1.6146 & 0.6193 & 5.1078 & -1164.88 & 8.5938 \\
\hline L2 & -5.2413 & -2.3187 & 2.9225 & 5.2412 & 2.3186 & 3.7799 & -3.78 & 1.4612 & 0.6843 & 4.8889 & -1301.13 & 11.0167 \\
\hline L3 & -5.4773 & -2.3775 & 3.0997 & 5.4772 & 2.3774 & 3.9273 & -3.9274 & 1.5498 & 0.6452 & 4.9759 & -1242.86 & 9.6398 \\
\hline ML1 & -3.5074 & -1.7929 & 1.7145 & 3.5074 & 1.7929 & 2.6501 & -2.6502 & 0.8572 & 1.1665 & 4.0964 & -6571.37 & 5.9399 \\
\hline ML2 & -3.6443 & -2.5011 & 1.1432 & 3.6443 & 2.5010 & 3.0726 & -3.0727 & 0.5716 & 1.7494 & 8.2586 & -6708.23 & 10.7441 \\
\hline ML3 & -3.7316 & -2.8978 & 0.8338 & 3.7316 & 2.8977 & 3.3146 & -3.3147 & 0.4169 & 2.3986 & 13.1768 & -6650.09 & 8.4556 \\
\hline
\end{tabular}

HOMO and LUMO, represents stability of structures and helps to characterize some significant issues including the kinetic stability as well as chemical reactivity of the molecule $[47,48]$. Chemical hardness is associated with the stability and reactivity of a chemical system. The values of HOMO-LUMO energy gap reflect the chemical activity of the molecule [49]. In order to evaluate the energetic behavior of the title compounds, we carried out calculations for ligand L1 complex ML1. The HOMO and LUMO energy calculated by B3LYP method in $6-311++G(d, p)$ basis set is presented in Table 4, Figure 6A, 6B shows the frontier orbitals shape. The plots of frontier molecular orbitals for L1 are shown the HOMO is localized on whole the azomethine (N25) nitrogen $(-\mathrm{CH}=\mathrm{N}-\mathrm{NH}-)$, hydrazine nitrogen (N27) and almost the phenolic oxygen (O29), and benzene ring. The weakly contribution on dinitro phenyl ring. The LUMO is localized mainly on the nitro group and dinitro phenyl ring, The weakly contribution on azomethine nitrogen and hydrazine nitrogen.

The frontier energy gap implies an electron density transfer to the benzene ring from the azomethine nitrogen (N25) and hydrazine nitrogen (N27) and phenolic oxygen and also explains the eventual charge transfer occurs within the compound. According to calculation, the energy band gap of HL1 reveals about $3.2293 \mathrm{eV}$ by B3LYP method at the mentioned basis set. The detail result in B3LYP is HOMO energy = $5.6761 \mathrm{eV}$, LUMO energy $=-2.4467 \mathrm{eV}$. The HOMO density of octahedral form of the complex ML1 is distributed over the metallic element $(73 \mathrm{Ru})$, phenolic ring, phenolic oxygen (710), azomethine nitrogen $(60 \mathrm{~N})$, nitrogen atom in hydrazine $(66 \mathrm{~N})$, nitro group and two bipyridine ring. The HOMO is mainly localized on phenolic ring, phenolic oxygen (710), azomethine nitrogen $(60 \mathrm{~N})$ and nitrogen atom in hydrazine $(66 \mathrm{~N})$ with strong contribution, on the metal $(73 R u)$ and carbon atoms of two bipyridine ring with a weak contribution,
The LUMO is localized on the metal $(73 R u)$, two bipyridine ring, and nitro group $(65 \mathrm{~N}, 68 \mathrm{O}, 69 \mathrm{O})$ with great contribution, on carbon atoms phenolic ring, phenolic oxygen $(710$, azomethine nitrogen $(60 \mathrm{~N})$ and nitrogen atom in hydrazine $(66 \mathrm{~N})$ with weak contribution. According to calculation, the energy band gap of Complex ML1 reveals about $1.7145 \mathrm{eV}$ by B3LYP method at the mentioned basis set. The detail result in $\mathrm{B} 3 \mathrm{LYP}$ is $\mathrm{HOMO}$ energy $=-3.5074 \mathrm{eV}$.

$$
\text { LUMO energy }=-1.7929 \mathrm{eV}
$$

\section{HOMO-LUMO energy gap $=1.7145 \mathrm{eV}$}

This small energy gap confirms the compounds with high chemical reactivity as well as high polarizability.

\subsection{Mulliken Atomic Charge}

We carried Mulliken atomic charge calculation has an important role in the application of quantum chemical calculation to molecular system because of atomic charges effect electronic structure, molecular polarizability, and dipole moment more a lot of properties of molecular systems [50]. The charge changes with methods presumably occur due to variation of the hybrid functional. Illustration of atomic charges plotted is shown in Figures a19-a21. In the complex ML1 all the hydrogen atoms have a net positive charge. The central metal (Ru73) atom has positive charge (1.2832e). The obtained atomic charge shows that the $\mathrm{H} 49$ atom has bigger positive atomic charge $(0.4494 \mathrm{e})$ than the other hydrogen atoms. This is due to the presence of electronegative oxygen atom (O72), the positive charges of hydrogen atom ( $\mathrm{H} 49)$ attracts the oxygen atom (O72). The carbon (C19) atom has bigger negative atomic charge $-0.3055 \mathrm{e}$ ) than the other carbon atoms. This is due to the presence of electronegative oxygen atom $(\mathrm{O} 71, \mathrm{O} 72)$. The oxygen (O70) atom of nitro group has bigger negative atomic charge $(-0.7185 e)$ than the other oxygen atoms. The 


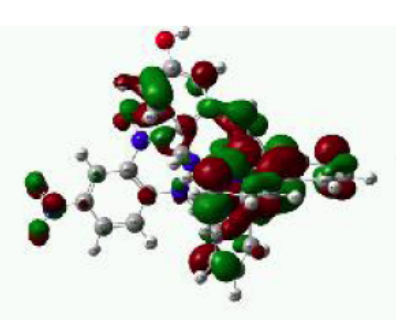

IUMO

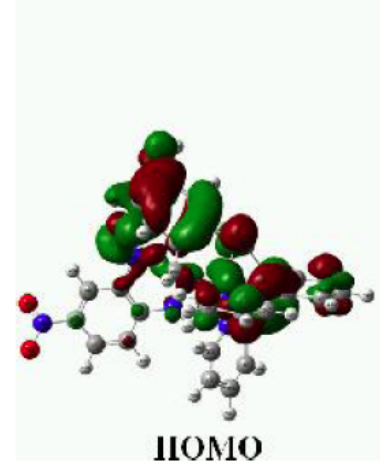

lixcited state

$$
\mathbf{E}_{\mathrm{TIMMO}}=-1.7929 \mathrm{cV}
$$

$\Lambda E=1.7145 \mathrm{cV}$

A
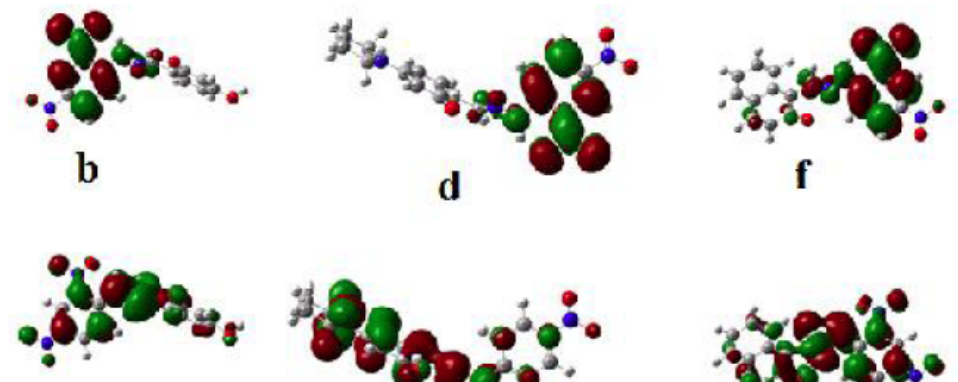

$\mathbf{a}$

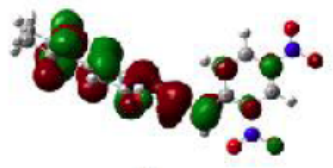

$\mathbf{c}$

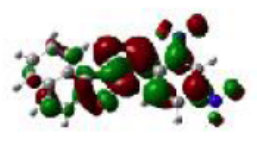

e

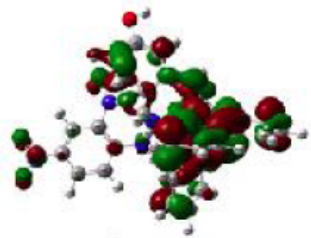

h

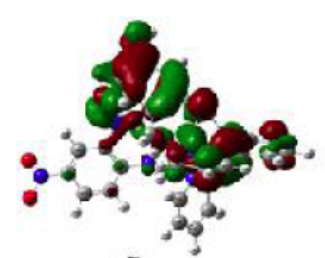

g

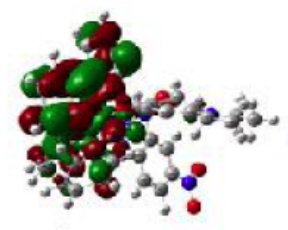

i

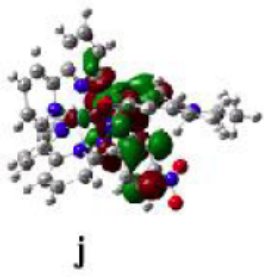

B
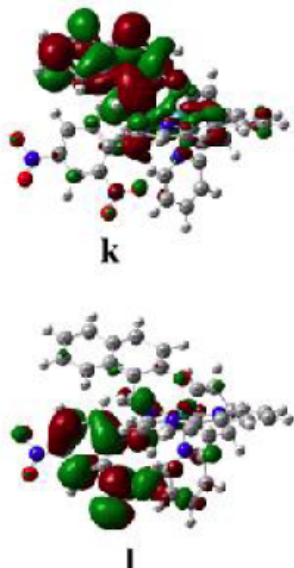

Figure 6: A: Atomic orbital compositions of the frontier molecular orbital of complex ML1.

B: Frontier molecular orbitals for ligands and the complexes: (a) HOMO of complex L1, (b) LUMO of complex L1, (c) HOMO of complex L2, (d) LUMO of complex L2, (e) HOMO of complex L3, (f) LUMO of complex L3, (g) HOMO of complex ML1, (h) LUMO of complex ML1, (i) HOMO of complex ML2, (j) LUMO of complex ML2, (k) HOMO of complex ML3, (I) LUMO of complex ML3. 


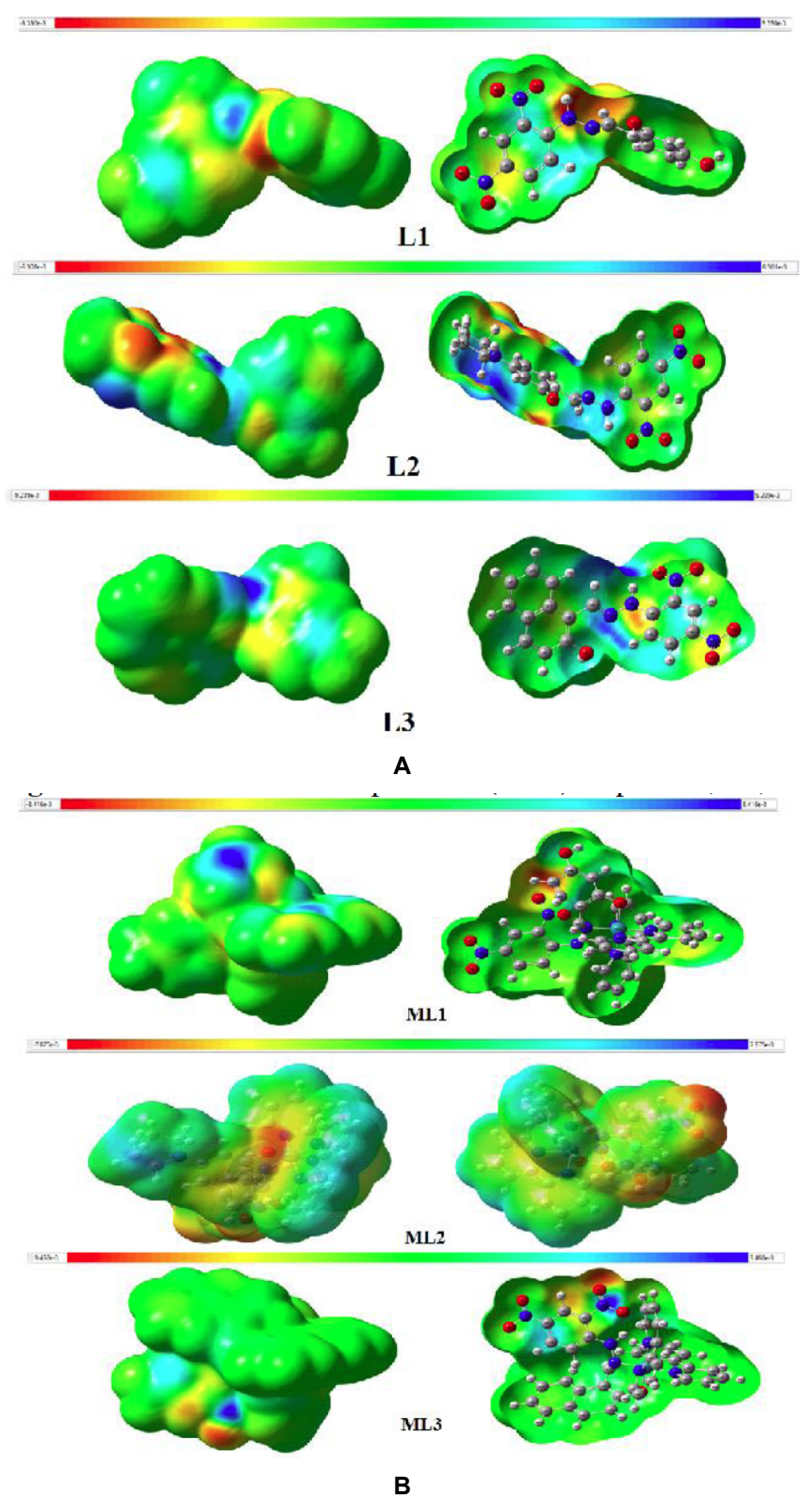

Figure 7: A: Molecular electrostatic potential (MEP) map of L1, L2, L3.

B: Molecular electrostatic potential (MEP) map of ML1, ML2, ML3.

charge of the nitrogen atom (N60) in imine group is $0.4633 \mathrm{e}$ and the charge of oxygen atom (O71) in phenolic group is $-0.5010 \mathrm{e}$. The results illustrate that the charge of the azomethine groups exhibits a negative charge, which are donor atoms. Considering the applied method used in the atomic charge calculation, the oxygen atoms in phenolic group and nitrogen atoms in azomethine groups exhibit a negative charge, which are donor atoms.

\subsection{Molecular Electrostatic Potential (MEP)}

The 3-D plot of molecular electrostatic potential (MEP) maps provides the isosurface values with the location of negative and positive electrostatic 
potentials. The MESP surface diagram is used to understand the reactive behavior of a molecule, the differences between nuclophilicity and electrophilicity may affect the proton donating or accepting ability of a compound [51]. While the negative electrostatic potential corresponds to an attraction of the proton by the concentrated electron density in the molecule (and is colored in the shades of red on the EPS surface), the positive electrostatic potential corresponds to the repulsion of the proton by atomic nuclei in regions where low electron density exists and the nuclear charge is incompletely shielded (and is colored in shades of blue). MEP was calculated at the B3LYP/6$311 \mathrm{G}(\mathrm{d}, \mathrm{p})$ optimized geometry of the ligands and complexes [52]. The MEP plots of L1 and ML1 are portrayed in Figure 7A, 7B. The red color is correlated with electron rich area whereas the blue color represents the electropositive sites [52-54]. MEP of L1 plots clearly indicate that on the maximum negative (red) region is localized on the azomethine nitrogen (N25) probably due to the attachment with hydrazine nitrogen atom (N27), minimum value of $-9.390 \mathrm{e}-3$. maximum positive (blue) region is localized on dinitro benzenene ring due to the hydrogen atoms, with a maximum value of $9.390 \mathrm{e}-3$ and the green represents regions of zero potential.

In EPS of ML1 indicates that on deprotonation of phenolic oxygen (O71), the additional negative charge mostly distributed over bipyridine nitrogen atoms. The negative (red) region is localized on the phenolic oxygen, with a minimum value of $-8.416 \mathrm{e}-3$. However, maximum positive (blue) region is localized on the bipyridine nitrogen probably due to the hydrogen atoms, with a maximum value of $8.416 \mathrm{e}-3$, and the green represents regions of zero potential. The optimized structures of complexes and ligands L1, L2, L3, ML2 and ML3 also have similar types of MEP and may have the same interactions, excepting that the molecular electrostatic potential value is varied.

\section{CONCLUSION}

We have synthesized and reported the characterization, photophysical, electrochemical and thermal studies of three new ruthenium complexes containing hydrazine schiff base ligands. Spectroscopic techniques including FT-IR, ${ }^{1} \mathrm{H}$ and ${ }^{13} \mathrm{C}$ NMR, and mass analysis were used to identify the synthesized products. The spectral results suggest that the presence of an octahedral geometry around the ruthenium metal. The three materials based on ML1, ML2, and ML3 have good stabilities and their thermal decomposition temperatures are $196^{\circ} \mathrm{C}, 192^{\circ} \mathrm{C}$, and $198^{\circ} \mathrm{C}$ respectively. To study the structural and electronic properties of the synthesized molecules, HOMO-LUMO energy gap, the Mulliken atomic charges as well as molecular electrostatic potential of title compounds were determined. All theoretical calculations were carried out by the more popular DFT methods, B3LYP, at $6-31+G(d, p)$ level of theory. The HOMO-LUMO energy gap as an important value for stability index revealed high chemical reactivity of synthesized compounds in chemical reactions.

\section{ACKNOWLEDGEMENT}

One of the authors S. Kamalesu thank Dr. K. Muralidharan, Associate Professor and UGCNetworking Centre, School of Chemistry, University of Hyderabad, for awarding the visiting research fellowship to use the facilities at School of Chemistry, University of Hyderabad, Hyderabad.

\section{SUPPLEMENTARY MATERIALS}

The supplementary materials can be downloaded from the journal website along with the article.

\section{REFERENCE}

[1] Ye M, Wen X, Wang M, locozzia J, Zhang N, Lin C, Lin Z. Recent advances in dye-sensitized solar cells: from photoanodes, sensitizers and electrolytes to counter electrodes. Mater Today 2015; 18; 155-162. https://doi.org/10.1016/i.mattod.2014.09.001

[2] Lior N. Energy resources and use: The present situation and possible paths to the future. Energy 2008; 33: 842-857. https://doi.org/10.1016/j.energy.2007.09.009

[3] Qin Y, Peng Q. Ruthenium Sensitizers and Their Applications in Dye-Sensitized Solar Cells. International Journal of Photoenergy 2012; 2012: 1-21.

https://doi.org/10.1155/2012/291579

[4] Gratzel M. Photoelectrochemical cells. Nature 2001; 414: 338-344.

https://doi.org/10.1038/35104607

[5] Silva MSP, Diógenes LCN, Zanoni KPS, Amaral RC, Carvalho IMM, Murakami Iha NY. Novel heteroleptic ruthenium complexes for dye sensitized solar. J Photochem Photobiol B 2016; 314: 75-80.

https://doi.org/10.1016/j.jphotochem.2015.08.012

[6] Argazzi R, Murakami Iha NY, Zabri H, Odobel F, Bignozzi CA. Design of molecular dyes for application in photoelectrochemical and electrochromic devices based on nanocrystalline metal oxide semiconductors. Coord Chem Rev 2004; 248: 1299-1316. https://doi.org/10.1016/j.ccr.2004.03.026

[7] Karkas MD, Johnston EV, Verho O, Akermark B. Artificial Photosynthesis: From Nanosecond Electron Transfer to Catalytic Water Oxidation. Acc Chem Res 2014; 47: 100-111. https://doi.org/10.1021/ar400076j

[8] Brennaman MK, Patrocinio AOT, Song W, Jurss JW, Concepcion JJ, Hoertz PG, Traub MC, Murakami Iha NY, Meyer TJ. Interfacial Electron Transfer Dynamics Following Laser Flash Photolysis of $\left[\mathrm{Ru}(\mathrm{bpy})_{2}\left(\left(4,4^{\prime}-\mathrm{PO}_{3} \mathrm{H}_{2}\right)_{2} \mathrm{bpy}\right)\right]^{2+}$ in 
$\mathrm{TiO}_{2}$ Nanoparticle Films in Aqueous Environments. ChemSusChem 2011; 4: 216-227.

https://doi.org/10.1002/cssc.201000356

[9] Concepcion JJ, Jurss JW, Brennaman MK, Hoertz PG, Patrocinio AOT, Murakami Iha NY, Templeton JL, Meyer TJ. Making Oxygen with Ruthenium Complexes. Acc Chem Res 2009; 42: 1954-1965.

https://doi.org/10.1021/ar9001526

[10] Wasylenko DJ, Ganesamoorthy C, Henderson MA, Koivisto $B D$, Osthoff HD, Berlinguette CP. Making Oxygen with Ruthenium Complexes. J Am Chem Soc 2010; 132: 1609416106. https://doi.org/10.1021/ja106108y

[11] Beer PD, Cadman J. Electrochemical and optical sensing of anions by transition metal based receptors. Coord Chem Rev 2000; 205: 131-155.

https://doi.org/10.1016/S0010-8545(00)00237-X

[12] Kapilashrami M, Zhang Y, Liu YS, Hagfeldt A, Guo. Probing the Optical Property and Electronic Structure of $\mathrm{TiO}_{2}$ Nanomaterials for Renewable Energy Applications. J Chem Rev 2014; 114: 9662-9707.

https://doi.org/10.1021/cr5000893

[13] Mathew S, Yella A, PengGao, Humphry-Baker R, Curchod FE, Astani NA, Tavernelli I, Rothlisberger U, Nazeeruddin KM, Gratzel M. Dye-sensitized solar cells with $13 \%$ efficiency achieved through the molecular engineering of porphyrin sensitizers. Nat Chem 2014; 6: 242-247. https://doi.org/10.1038/nchem.1861

[14] Wei J, Zhang TT, Jia J, Wu HS. Effect of $\mathrm{COOH}$ group on the performance of rhenium (I) tricarbonyl complexes with tetrathiafulvalene-fused phenanthroline ligands as dyes in DSSC: DFT/TD-DFT theoretical investigations. Struct Chem 2015; 26: 421-430. https://doi.org/10.1007/s11224-014-0496-1

[15] Liu MZ, Johnston MB, Snaith HJ. Efficient planar heterojunction perovskite solar cells by vapour deposition. Nature 2013; 501: 395-398.

https://doi.org/10.1038/nature12509

[16] Ozawa H, Yamamoto Y, Kawaguchi H, Shimizu R, Arakawa $H$. Ruthenium Sensitizers with a Hexylthiophene-Modified Terpyridine Ligand for Dye-Sensitized Solar Cells: Synthesis, Photo- and Electrochemical Properties, and Adsorption Behavior to the $\mathrm{TiO}_{2}$ Surface. ACS Appl Mater Interfaces 2015; 7: 3152-3161. https://doi.org/10.1021/am507442s

[17] Ghosh B, Naskar S, Naskar S, Espinosa A, Hau SCK, Mak TCW, Sekiya R, Kuroda R, Chattopadhyay SK. Heteroleptic $\mathrm{Ru}(\mathrm{II})$ complexes containing aroyl hydrazone and 2,2'bipyridyl: Synthesis, X-ray crystal structures, electrochemical and DFT studies. Polyhedron 2014; 72: 115-121.

https://doi.org/10.1016/j.poly.2014.01.031

[18] Tan L, Zhang X, Mao L. Novel zinc porphyrin sensitizers for dye-sensitized solar cells: Synthesis and spectral, electrochemical, and photovoltaic properties. J Mol Struct 2013; 1035: 400-406. https://doi.org/10.1016/j.molstruc.2012.12.003

[19] a) Wu YH, Chen L, Yu J, Tong SL, Yan Y. Synthesis and spectroscopic characterization of meso-tetra (Schiff-base substituted phenyl) porphyrins and their zinc complexes. Dyes Pigments 2013; 97: 423-428.

https://doi.org/10.1016/j.dyepig.2012.12.032

b) Zoubi WAL, Kandil F, Chebani MK. The synthesis of (N2O2S2)-Schiff base ligands and investigation of their ion extraction capability from aqueous media. Spectrochim Acta A 2011; 79: 1909-1914.

https://doi.org/10.1016/j.saa.2011.05.087

c) Zoubi WAL, Kandil F, Chebani MK. The synthesis of N2O2-Schiff base ligand and bulk liquid membrane transport of Cu2+. Arabian J Chem 2006; 9: 626-632.

https://doi.org/10.1016/j.arabjc.2011.05.006
[20] Walter MG, Rudine AB, Wamser CC. Porphyrins and phthalocyanines in solar photovoltaic cells. J Porphyr Phthalocyanines 2010; 14: 759-792. https://doi.org/10.1142/S1088424610002689

[21] Zhang X, Zhu Y, Wu X, He H, Wang G, Li Q. Meso-Schiffbase substituted porphyrin dimer dyes for dye-sensitized solar cells: synthesis, electrochemical, and photovoltaic properties. Res Chem Intermed 2015; 41: 4227-4241. https://doi.org/10.1007/s11164-013-1525-1

[22] Jeevadason AW, Murugavel KK, Neelakantan MA. Review on Schiff bases and their metal complexes as organic photovoltaic materials. Renew Sustainable Energy Rev 2014; 36: 220-227.

https://doi.org/10.1016/j.rser.2014.04.060

[23] a) Tunc T, Tezcan H, Sahin E, Dilek N. Synthesis, Crystal Structure, and Spectroscopic Studies of N-(4Bromobenzylidene)-N'-(2-Pyridyl) Hydrazine Schiff Base Molecule. Mol Cryst Liq Cryst 2012; 552: 194-208. https://doi.org/10.1080/15421406.2011.591702

b) Zoubi WA, Al-Hamdani AAS, Kaseem M. Synthesis and antioxidant activities of Schiff bases and their complexes: a review. Appl Organomet Chem 2016; 30: 810-817.

https://doi.org/10.1002/aoc.3506

c) Zoubi WA, Ko YU. Organometallic complexes of Schiff bases: Recent progress in oxidation catalysis. J Organomet Chem 2016; 822: 173-188.

https://doi.org/10.1016/j.jorganchem.2016.08.023

[24] a) Despaigne AAR, Da Silva JG, Carmo ACM, Piro OE, Castellano EE, Beraldo H. Copper(II) and zinc(II) complexes with 2-benzoylpyridine-methyl hydrazone J Mol Struc 2009; 920: 97. https://doi.org/10.1016/j.molstruc.2008.10.025

b) Zoubi WAL, Kandil F, Chebani MK. Solvent extraction of chromium and copper using Schiff base derived from terephthaldialdehyde and 5-amino-2-methoxy-phenol Arabian J Chem 2016; 9: 526-632.

https://doi.org/10.1016/i.arabjc.2011.06.023

c) Zoubi WAL, Kandil F, Chebani MK. Synthesis of New N,N'bis(2-aminothiophenol)- $\alpha, \alpha^{\prime}$-bis(5-bromocarboxylidene phenoxy)xylene and their Liquid Membrane Transport of Copper Cations. Sep Sci Technol 2013; 48: 501-507. https://doi.org/10.1080/01496395.2012.703750

[25] a) Zoubi WAL, Kandil F, Chebani MK. The Synthesis and Characterization of New Schiff Bases and Investigating them in Solvent Extraction of Chromium and Copper. Sep Sci Technol 2012; 47: 1754-1761. https://doi.org/10.1080/01496395.2012.660554

b) Sridhar R, Perumal PT. Synthesis of Novel 1-H-Pyrazole4-carboxylic Acid Esters by Conventional and Microwave Assisted Vilsmeier Cyclization of Hydrazones. Synth Commun 2003; 33: 1483-1488. https://doi.org/10.1081/SCC-120018766

[26] Vogel Al, Text Book of Practical Organic Chemistry. fifth edn London; Longman 1989.

[27] Mermion ME, Takeuchi, KJ. Ruthenium(1V)-Oxo Complexes The Novel Utilization of Tertiary Pnictogen Ligands. J Am Chem Soc 1998; 110: 1472-1480.

https://doi.org/10.1021/ja00213a019

[28] Frisch MJ, Trucks GW, Schlegeletal, HB. Gaussian 09, Revision A.01 Gaussian, Wallingford Conn USA 2009.

[29] Becke AD. Densityfunctional thermochemistry III. The role of exact exchange. J Chem Phys 1993; 98: 5648-5652. https://doi.org/10.1063/1.464913

[30] Cohen AJ, Sanchez PM, Yang W. Challenges for Density Functional Theory. Chem Rev 2012; 112: 289-320. https://doi.org/10.1021/cr200107z

[31] Khera B, Sharma AK, Kaushik NK. Bis(indenyl)titanium(IV) and zirconium(IV) complexes of monofunctional bidentate salicylidimines. Polyhedron 1983; 2: 1177-1180. https://doi.org/10.1016/S0277-5387(00)84353-3 
[32] Jayabalakrishnan C, Natarajan K. Ruthenium(II) carbonyl complexes with tridentate Schiff bases and their antibacterial activity. Trans Met Chem 2002; 27: 75-79. https://doi.org/10.1023/A:1013437203247

[33] Jayabalakrishnan C, Karvembu R, Natarajan K. Catalytic and antimicrobial activities of new ruthenium(II) unsymmetrical Schiff base complexes. Trans Met Chem 2002; 27: 790-794. https://doi.org/10.1023/A:1020341703855

[34] Khaled S, Ahmed MZ, Khan FG, Ahmed SK. Synthesis, Characterization, and Photophysical Studies of Some Novel Ruthenium(II) Polypyridine Complexes Derived from Benzothiazolyl hydrazones. International Journal of Inorganic Chemistry 2013; 2013: 1-7.

https://doi.org/10.1155/2013/212435

[35] Nakamoto K. Infrared and Raman Spectra of Inorganic and Coordination Compounds, 4th edition, New York: John Wiley \& Sons 1986.

[36] Yaul SR, Yaul AR, Pethe V. Synthesize and characterization of Transition Metal complexes with N, O-Chelating Hydrazone Schiff Base Ligand. Am-Euras J Sci Res 2009; 4: 229-234.

[37] Manikandan R, Viswanathamurthi $P$, Muthukumar $M$. Ruthenium(II) hydrazone Schiff base complexes Synthesis, spectral study and catalytic applications. Spectrochim Acta A 2011; 83: 297-303. https://doi.org/10.1016/j.saa.2011.08.033

[38] Yin DD, Jiang YL, Shan. L, Synthesis, characterization of diorganotin (IV) schiff base complexes and their in vitro antitumor activity. Chin J Chem 2001; 19: 1136-1140. https://doi.org/10.1002/cjoc.20010191122

[39] Prabhu RN, Ramesh R. Synthesis, structural characterization, electrochemistry and catalytic transfer hydrogenation of ruthenium(II) carbonyl complexes containing tridentate benzoylhydrazone ligands. J Organomet Chem 2012; 18: 43-51.

https://doi.org/10.1016/j.jorganchem.2012.08.002

[40] Kumar KN, Ramesh R. Synthesis, characterization, redox property and biological activity of $\mathrm{Ru}(\mathrm{II})$ carbonyl complexes containing $\mathrm{O}, \mathrm{N}$-donor ligands and heterocyclic bases. Spectrochim Acta A 2004; 60: 2913-2918. https://doi.org/10.1016/j.saa.2004.02.011

[41] Thilagavathi N, Manimaran A, Priya NP, Sathya N, Jayabalakrishnan C. Synthesis, characterization, electrochemical, catalytic and antimicrobial activity studies of hydrazone Schiff base ruthenium(II) complexes. Appl Organomet Chem 2010; 24: 301-307.

[42] Sivagamasundari M, Ramesh R. Luminescent property and catalytic activity of $\mathrm{Ru}(\mathrm{II})$ carbonyl complexes containing $\mathrm{N}, \mathrm{O}$ donor of 2-hydroxy-1-naphthylideneimines. Spectrochim Acta Mol Biomol Spectrosc 2007; 66: 427-433. https://doi.org/10.1016/j.saa.2006.03.017

[43] Chen CY, Wu SJ, Wu CG, Chen JG, Ho KC. A Ruthenium Complex with Superhigh Light-Harvesting Capacity for DyeSensitized Solar Cells. Angew Chem Int Ed 2006; 45: 58225825.

https://doi.org/10.1002/anie.200601463
[44] Kar NK Singh MK, Lal RA. Synthesis and spectral studies on monometallic ruthenium (III) complexes of $\mathrm{N}-(2-$ hydroxysalicyliden-1-yl)methylenebenzoylhydrazide. Arab J Chem 2017; 10(Suppl 1): S76-S80.

https://doi.org/10.1016/j.arabjc.2012.05.007

[45] Xiao L, Liu Y, Xiu Q, Zhang L, Guo L, Zhang H, Zhong C. Novel polymeric metal complexes as dye sensitizers for Dyesensitized solar cells based on poly thiophene containing complexes of 8-hydroxyquinoline with $\mathrm{Zn}(\mathrm{II}), \mathrm{Cu}(\mathrm{II})$ and $\mathrm{Eu}(\mathrm{III})$ in the side chain. Tetrahedron 2010; 66: 2835-2842. https://doi.org/10.1016/j.tet.2010.02.039

[46] Kurt M, Sas EB, Can M, Okur S, Icli S, Demic S, Karabacak $M$, Jayavarthanan $T$, Sundaraganesan $N$. Synthesis and spectroscopic characterization on 4-(2,5-di-2-thienyl-1Hpyrrol-1-yl) benzoic acid: A DFT approach. Spectrochim Acta Mol Biomol Spectrosc 2016; 152: 8-17. https://doi.org/10.1016/j.saa.2015.07.058

[47] Migalska-Zalas A, Luc J, Sahraoui B, Kityk IV. Kinetics of third-order nonlinear optical susceptibilities in alkynyl ruthenium complexes. Opt Mater 2006; 28: 1147-1151. https://doi.org/10.1016/j.optmat.2005.06.018

[48] Ravikumar C, Hubert Joe I, Jayakumar VS. Charge transfer interactions and nonlinear optical properties of push-pul chromophore benzaldehyde phenylhydrazone: A vibrational approach. Chem Phys Lett 2008; 460: 552-558. https://doi.org/10.1016/j.cplett.2008.06.047

[49] Govindarajan M, Karabacak M. Spectroscopic properties, NLO, HOMO-LUMO and NBO analysis of 2,5-Lutidine. Spectrochim Acta Mol Biomol 2012; 96: 421-435. https://doi.org/10.1016/j.saa.2012.05.067

[50] Ebrahimi H, Had JS, Al-Ansari HS. Spectroscopic properties, NLO, HOMO-LUMO and NBO analysis of 2,5-Lutidine. J Mol Struct 2013; 1039: 37-45. https://doi.org/10.1016/j.molstruc.2013.01.063

[51] Yesilkaynak T, Binzet G, Emen FM, Florke U, Kulcu N, Arslan $\mathrm{H}$. Theoretical and experimental studies on $\mathrm{N}-(6-$ methylpyridin-2-yl-carbamothioyl)biphenyl-4-carboxamide. Eur J Chem 2010; 1: 1-5. https://doi.org/10.5155/eurjchem.1.1.1-5.3

[52] Mishra S, Chaturvedi D, Kumar N, Tandon P, Siesler HW. An ab initio and DFT study of structure and vibrational spectra of $Y$ form of Oleic acid: Comparison to experimental data. Chem Phys Lipids 2010; 163: 20. https://doi.org/10.1016/j.chemphyslip.2009.11.006

[53] Karmakar S, Mardanya S, Maity D, Baitalik S. Polypyridylimidazole based Os(II) complex as optical chemosensor for anions and cations and multi-readout molecular logic gates and memory device: Experimental and DFT/TDDFT study. Sensors Actuators B Chem 2016; 226: 388-402. https://doi.org/10.1016/j.snb.2015.11.104

[54] Shkir M, Muhammad S, AlFaify S, Irfan A, Patil PS, Arora M, Algarni $\mathrm{H}$, Zhang JP. An investigation on the key features of a D-ח-A type novel chalcone derivative for opto-electronic applications. Rsc Adv 2015; 5: 87320-87332. https://doi.org/10.1039/C5RA13494C 